\title{
THE USE OF THE MASS SPECTROMETER TO MEASURE DEUTERIUM IN BODY FLUIDS ${ }^{1}$
}

\author{
By A. K. SOLOMON, I. S. EDELMAN,2 ANd SIDNEY SOLOWAY 3 \\ (From the Biophysical Laboratory, Harvard Medical School, and the Surgical Research \\ Laboratory, Peter Bent Brigham Hospital and the Department of Surgery, \\ Harvard Medical School, Boston)
}

(Submitted for publication March 20, 1950; accepted, June 26, 1950)

\section{INTRODUCTION}

The use of deuterium oxide $\left(\mathrm{D}_{2} \mathrm{O}\right)$ for the measurement of total body water is based on the principle of isotopic dilution (1). Hevesy and Hofer (2) were the first to report that the volume available for distribution of injected $\mathrm{D}_{2} \mathrm{O}$ in the human approximates closely the total body water, and in addition, $\mathrm{D}_{2} \mathrm{O}$ provides a practical means for studying water metabolism. Their findings have been confirmed by numerous investigators who have found that total body water as measured with $\mathrm{D}_{2} \mathrm{O}$ agrees well with estimates based on desiccation, specific gravity, antipyrine and tritium oxide dilution in rats, rabbits, guinea pigs, and humans (2-11). The primary inherent source of error in this method lies in the exchange of deuterium atoms with labile hydrogen atoms of organic molecules (12-14). Since exchange occurs rapidly $(13,14)$ and represents only a small loss of deuterium from the water stores $(3,13,14,15)$, it does not affect the general validity of the method.

The technique involves a very large dilution of the isotopic compound, so that the precise accuracy with which the $\mathrm{D}_{2} \mathrm{O}$ is measured becomes the key factor in obtaining quantitative estimates of total body water. In order to obtain a high order of accuracy we have used the mass spectrometer in the measurement of deuterium concentration in body fluids. In this paper we are reporting the procedure, calibration techniques, and the accuracy obtained in such measurements.

\footnotetext{
1 This work has been supported in part by the Office of Naval Research, the Atomic Energy Commission, and the American Cancer Society. The deuterium has been supplied in part by the Isotopes Division of the Atomic Energy Commission.

2 Atomic Energy Commission Postdoctoral Research Fellow in the Medical Sciences.

8 Now at the Public Health Research Institute of the City of New York.
}

The inherent error in the method, i.e., the loss of deuterium by exchange, has been estimated as having a water equivalent of $0.5 \%$ to $2.0 \%$ of the body weight and is probably close to $1.0 \%$ to $1.5 \%(3,13,14,15)$. Thus, for the average adult, results calculated by the $\mathrm{D}_{2} \mathrm{O}$ method are too high by an estimated $700-1,000 \mathrm{ml}$. of body water. This figure sets a limit on the accuracy which can be achieved in total body water studies. Consequently, accuracy of the method within 1 liter of the approximately 45 liter total is considered acceptable. For a $70 \mathrm{~kg}$. adult injected with 80 to $100 \mathrm{gm}$. of $99.9 \% \mathrm{D}_{2} \mathrm{O}$, the equilibrium concentration will be close to 0.200 volume \% $\mathrm{D}_{2} \mathrm{O}$. In order to satisfy the criterion of accuracy, the acceptable error is limited to $\approx 0.004$ volume $\% \mathrm{D}_{2} \mathrm{O}$ (at this concentration, volume $\% \mathrm{D}$ is equivalent to atom $\% \mathrm{D})$.

\section{CONVERSION OF SAMPLE TO HYDROGEN GAS}

The hydrogen converter, which serves to prepare gas samples for the spectrometer, is a gas train modeled after a converter designed by Rittenberg and Graff (15a). Essentially the train consists of an oxidizing furnace, a reduction furnace, and a Toeppler pump. The reduction furnace contains a pyrex tube filled with zinc granules; it is operated at about $390^{\circ} \mathrm{C}$. A single charge of zinc is usually sufficient to last for the preparation of 150 samples. As the charge becomes exhausted, the temperature of the furnace is gradually raised until a small fraction of the zinc is melted. When necessary oxygen gas is used to oxidize the sample and serves also to sweep it along the train.

Approximately $0.03 \mathrm{ml}$. of water, plasma, or urine is pipetted quickly into a small platinum boat and inserted into the Vycor tube some distance from the oxidizing furnace. The evolution of the vapor from the water samples is speeded by 


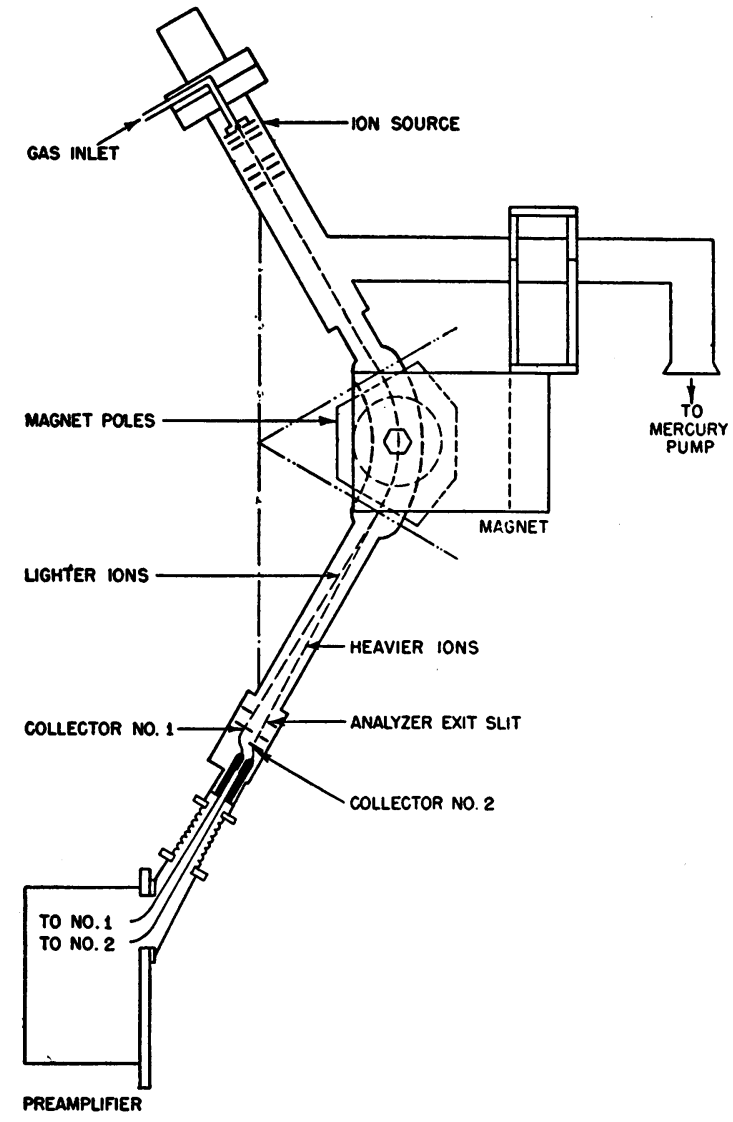

Fig. 1. Mass Spectrometer

gentle heating; no heat is applied to urine or plasma. The water is collected in a dry-ice trap, and the system is then evacuated so that the sample is distilled through the zinc furnace and pumped into the sample bulb by the Toeppler pump. If a single pass through the furnace does not reduce all the sample, it is discarded and the temperature of the furnace raised for the next sample.

\section{THE MASS SPECTROMETER}

The mass spectrometer, as shown in Figure 1, is a 60-degree sector instrument of the type described by Nier (16). The accelerating tube was built in the shops of the University of Minnesota, and the electronic and accessory apparatus constructed according to drawings supplied by Nier. In order to obtain a better vacuum in the accelerating tube, a two-stage metal mercury pump was used to replace the glass mercury pump specified. Although the vacuum was satisfactory, a most disturbing anomalous effect was observed in early experiments when hydrogen samples were introduced into the system. The pressure, as measured on an ionization gauge, varied erratically. This effect which has also been observed by others (17-20), was due to back diffusion of the gas through the jets of the mercury pump. To correct it, redesigned jets were installed in the pump, the fore-vacuum system was brought to the lowest possible vacuum, and the heater on the mercury pump was run at a temperature higher than normal.

The spectrometer has two collecting slits and amplifiers for the simultaneous measurement of two isotopes of heavier elements. Unfortunately, the double collection system cannot be used for hydrogen due to the large separation between the mass 2 and mass 3 peaks. As a result, it has proved necessary to impose stringent requirements on the various regulating systems. The voltage regulators for the amplifiers and for the high voltage supply have been redesigned. The emission regulator has been replaced with one utilizing an additional stage of amplification.

The hydrogen and deuterium ions are formed in the ion-source by bombardment of the gas with a beam of electrons of 75 volts energy. As initially designed, a permanent magnet is used to focus the electrons along a path perpendicular to the direction of ion beam acceleration. As pointed out by Jordan and Coggeshall (21), this electron focussing magnet is responsible for many sources of error in mass abundance measurements. We have obtained a satisfactory ion beam in the absence of this magnet by placing the filament which emits the electrons very close to the first slit which defines the electron beam. With a total emission current from the filament of 360 microamperes, we have collected 12 microamperes of effective electron current in a trap placed at the end of the electron trajectory. With a trap current of 12 microamperes, it is possible to collect enough hydrogen ions to produce a potential of 15 to 20 volts across a 40,000 megohm resistor.

It is possible to bring the ion peak onto the collector plate by holding the main magnetic field constant and adjusting the ion accelerating potential until the ion current is at a maximum. Or, the ion accelerating potential may be held constant and the magnetic field be altered to bring 
first mass 3 and then mass 2 onto the collector plate. For work with hydrogen, the second method, magnetic scanning, is to be preferred, since it eliminates many errors of discrimination between ions of mass 2 and mass 3 within the ion source. The necessary small modifications have been made to the spectrometer to simplify magnetic scanning.

One advantage in work with hydrogen is that in the low mass region there are very few possible contaminants, and one need not worry about background peaks in this region arising from contamination inside the tube. In practice, this means that the tube needs to be outgassed only at infrequent intervals. Further, since the separation between peaks is very great, the beam may be collected on the wider of the two collecting plates. Since the plate is much broader than the peak, it is possible to tolerate some small shifts in position of the ion beam on the collector. This operates to reduce slightly the requirements for stability of the ion accelerating potential and the magnetic field.

\section{SOURCES OF ERROR}

\section{a) In preparing the samples}

The errors in preparing gas samples are threefold: contamination, memory, and fractionation.

Contamination may arise from exposure of the sample to air, which will result in exchange between the sample and water vapor $(13,22)$. Therefore, in handling samples, care must be taken to limit this exposure. Samples are sealed in ampoules immediately after being drawn and are kept in a frozen sate. The calibration standards are kept airtight by storing in a syringe with the needle tip corked and the barrel sealed with an Apiezon vacuum grease film. A thermocouple gauge is used to measure the air pressure in the converter; it serves to warn of possible air leaks. Another source of contamination is from dissolved volatile substances in blood and urine, such as ketone bodies, alcohol, lipids and ammonia compounds. To guard against combustion of these substances to water, the oxidizing furnace is not used when converting serum and urine.

The memory effect is due to exchange in the converter while the sample is in the water phase, particularly with water films on the glass walls (22). The data in Table I show the magnitude of
TABLE I

Memory effect

Previous sample: 0.0145 atom $\% \mathrm{D}$

$\begin{array}{cc}\text { Run number } & \text { Atom \% D } \\ 1 & 0.180 \\ 2 & 0.208 \\ 3 & 0.235 \\ 4 & 0.228 \\ 5 & 0.235\end{array}$

this effect which is a function of the difference in concentrations in the two successive samples. At low concentrations, discarding the first two bulbs converted will largely eliminate this source of error. We convert to obtain five gas bulbs per sample, discard the first two, run the last three and take the mean atom $\%$ as the determined value of the sample. Our converter is not used on samples with deuterium content greater than $0.799 \%$.

The third source of error is fractionation. This phenomenon is dependent on the vapor pressure and diffusion rate differences (22) of $\mathrm{D}_{2} \mathrm{O}, \mathrm{HDO}$, and $\mathrm{H}_{2} \mathrm{O}$. Thus, in collecting fractions of samples converted, we found, as shown in Table II, the head fraction lighter and the tail fraction heavier than the average of all fractions. This source of error can be avoided by either collecting only the middle fraction or converting each sample to completion. We prefer the latter technique.

\section{b) In the spectrometer}

Many of the sources of error common to 60 degree sector tubes are eliminated by the use of magnetic scanning and the absence of the electron focussing magnet. Nonetheless, there remain other variables which have to be taken into consideration. One source of error is a depression in the apparent $\mathrm{D} / \mathrm{H}$ ratio when foreign gases are present. Since air is the major foreign gas which may plague us, all samples are checked for nitro-

TABLE II

Fractionation in Converter

\begin{tabular}{l|c|c|c}
\hline \hline \multicolumn{1}{c|}{ Fraction } & Head & Middle & Tail \\
\hline $\begin{array}{l}\text { No. of runs } \\
\text { Atom \% D }\end{array}$ & 2 & 3 & 1 \\
Average of all runs & 0.174 & 0.177 & 0.186 \\
\hline $\begin{array}{l}\text { No. of runs } \\
\text { Atom \% D } \\
\text { Average of all runs }\end{array}$ & 0.927 & 0.945 & \\
\hline
\end{tabular}


gen content, and high ones are discarded. It might be possible to have a memory effect within the spectrometer tube due to adsorption of $\mathrm{H}_{2}$ gas on the metal surfaces. However, control experiments have indicated that this effect does not occur over our normal concentration ranges.

Another error might arise from the relative specific ionization of hydrogen and deuterium. Honig (23) has shown that the total ionization cross sections for $\mathrm{H}_{2}{ }^{+}, \mathrm{D}_{2}{ }^{+}$and probably $\mathrm{HD}^{+}$are the same within $4 \%$. Nevertheless, a small number of monatomic $\mathrm{H}^{+}$ions will be produced by electron impact on $\mathrm{H}_{2}$, and thus the intensity of the mass 2 beam will be depressed. Likewise, $\mathrm{D}^{+}$ and $\mathrm{H}^{+}$ions lost from the $\mathrm{HD}^{+}$fraction will cause a decrease of mass 3 , and the $\mathrm{D}^{+}$ions will contribute to an increase in mass 2. Bauer and Beach (24) have shown this loss amounts to $2.54 \%$ for $\mathrm{H}^{+}$from $\mathrm{H}_{2}{ }^{+}$, and $1.36 \%$ for $\mathrm{D}^{+}$from $\mathrm{D}_{2}{ }^{+}$, at an electron accelerating voltage of 75 volts such as we use, and further, that the ratio of $\mathrm{H}^{+}$ lost to $\mathrm{D}^{+}$lost is virtually independent of voltage up to 100 volts. Friedel and Sharkey (25) have confirmed the ratio of these two losses; further, they have observed that at 70 volts the losses of monatomic ions from $\mathrm{H}^{2}$ and $\mathrm{HD}$ are practically equal and are twice the amount of monatomic ions lost from $\mathrm{D}_{2}$. The ratio

$$
\frac{\frac{\mathrm{H}^{+} \text {lost from } \mathrm{H}_{2}{ }^{+}}{\mathrm{H}_{2}^{+}}}{\frac{\left(\mathrm{H}^{+}+\mathrm{D}^{+}\right) \text {lost from } \mathrm{HD}^{+}}{\mathrm{HD}^{+}}}
$$

has the value 1.03 , and hence all figures for the mass $3 /$ mass 2 ratio should be divided by this factor. The determination of deuterium in biological work does not necessitate measurements of high percentage deuterium samples, and hence the contribution of $\mathrm{D}^{+}$ions to the mass 2 peak can be neglected.

As pointed out by Inghram (26), an additional source of error may arise in non-linearities in the input resistor $\left(4 \times 10^{10} \mathrm{ohms}\right)$ of the amplifier over the range from 0.001 to 20.0 volts used in these experiments. Feed-back amplifiers such as used in this spectrometer should be free of any other non-linearities, an assumption which has been checked experimentally on similar amplifiers by Inghram. The non-linearity errors may be measured directly as he describes, or they can be evaluated by calibration against measured deuterium dilutions, as we have done. For biological measurements, in which relative rather than absolute values of this ratio are required, it is sufficient to calibrate the system over the limited range of dilutions and ion beam currents which will be met in practice.

In view of the large percentage difference in molecular weight between mass 2 and mass 3 , it is important to compensate for any fractionation of the gases entering the spectrometer. Honig (23, 27) has shown that fractionation occurs in the source, the region of the spectrometer in which the gas is ionized. Therefore, it is necessary to multiply the observed mass $3 /$ mass 2 ratio by a pumping speed correction of $\sqrt{3 / 2}=1.225$ to compensate for the greater rate at which mass 2 is removed from the source.

Fractionation may also occur between the gas reservoir and the source in the spectrometer. To avoid this, Nier (16) has designed a long capillary gas inlet system constricted at the end near the spectrometer. In such a system the viscous gas flow (flow independent of molecular weight) through the capillary overcomes any tendency for fractionation at this constriction, and hence no discrimination between the two masses is expected. The mass $3 /$ mass 2 ratio as measured on the spectrometer is constant for up to seven successive runs taken from a single filling of the reservoir; therefore, the gas composition in the reservior remains constant, proving that the leak does not fractionate.

The major uncompensated sources of error arise from drift in the amplifier and in the emission current. Under the best conditions, the short time amplifier drift is under 0.2 millivolt. After the amplifiers, which are not turned off, have been in operation for two or three days, the long time drift disappears. Long time drifts in emission current are corrected at the beginning of each run, and short time drifts cannot be detected on the trap current meter. The uncompensated drifts may be considered as random errors.

It must be pointed out that the stability of the instrument is temperature and humidity dependent. When the ambient temperature rises above $90^{\circ} \mathrm{F}$., it is wiser not to attempt to obtain accurate results. 


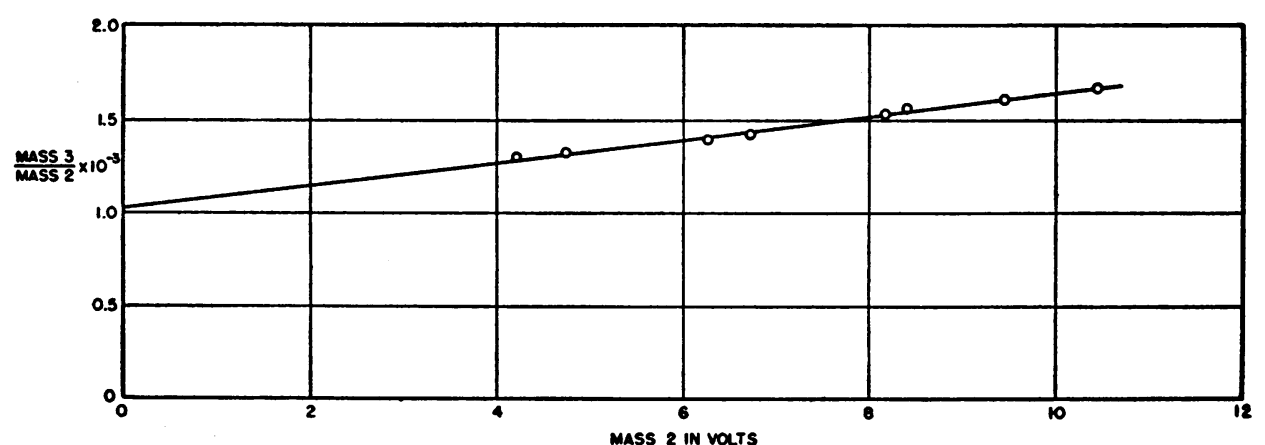

Fig. 2. Mass 3/Mass 2 Ratio as a Function of Pressure of Hydrogen in the System The intercept with 0 ordinate gives the true ratio for the sample.

\section{CALCULATION OF RESULTS}

\section{a) $\mathrm{HHH}^{+}$effect}

As stated by Bleakney (28) in 1932, the intensity of the mass 3 peak is dependent not only on the presence of $\mathrm{HD}^{+}$ions but also on $\mathrm{HHH}^{+}$ ions, formed by the collision between $\mathrm{HH}^{+}$and $\mathrm{H}_{2}$. The intensity of the $\mathrm{HHH}^{+}$contribution is a linear function of the pressure of $\mathrm{H}_{2}$. This can be measured directly by the intensity of the mass 2 peak, as shown in Figure 2.

The $\mathrm{D} / \mathrm{H}$ ratio can be determined from the intercept of this curve with the ordinate zero. We had hoped to determine the absolute slope of this curve from the average of a long series of runs, and then to use the value thus determined to apply a calculated correction to a determination made at one pressure only.

The slope is, however, very dependent on trap current; at 12 microamperes, a 1 microampere increase in trap current causes a $6 \%$ decrease in slope. Further, operation at the same value of trap current is not sufficient to control the slope absolutely, and so we always plot the curve in order to obtain accurate values.

b) The atom \% deuterium formula and equilibrium constant

By definition, the formula for atom $\% \mathrm{D}$ is given by :

(1) Atom $\% \mathrm{D}=\frac{\mathrm{D}}{\mathrm{H}+\mathrm{D}} \times 100$

for the reaction:

$$
\mathrm{HH}+\mathrm{DD} \rightleftharpoons 2 \mathrm{HD} \text { (gas phase). }
$$

This can be rewritten, as pointed out by Rittenberg (29) for $\mathrm{N}^{\mathbf{1 5}}$.

(2) Atom $\% \mathrm{D}=\frac{[\mathrm{HD}]+2[\mathrm{DD}]}{2[\mathrm{HH}]+2[\mathrm{HD}]+2[\mathrm{DD}]} \times 100$.
Since we determine the apparent ratio of $\frac{[\mathrm{HD}]}{[\mathrm{HH}]}$ or the $\frac{\text { Mass } 3}{\text { Mass } 2}$ ratio, with the spectrometer, the entire formula can be expressed in terms of this ratio, if the equilibrium constant for the gas phase reaction is known. The experimental determination $(24,30)$ of this constant gives a figure closely approximating 3.80 at $410^{\circ} \mathrm{C}$., which is the average temperature at which our zinc furnace is run.

Thus for:

$\mathrm{R}=\frac{[\mathrm{HD}]}{[\mathrm{HH}]}$, as measured in the spectrometer by $\frac{\text { mass } 3}{\text { mass } 2}$ and

(3) $\mathrm{K}^{\mathbf{4 1 0} \text { oc. }}=3.80=\frac{[\mathrm{HD}]^{\mathbf{3}}}{[\mathrm{HH}] \times[\mathrm{DD}]}$,

and taking into account the pumping speed correction factor of 1.225 ,

(4) Atom \% $\mathrm{D}=\frac{\mathrm{R}(2 \mathrm{R}+4.66)}{2\left(\mathrm{R}^{2}+4.66 \mathrm{R}+5.70\right)} \times 100$.

This formula can be simplified by using the approximate value of $\mathrm{K}=4.0$. In this case the formula is

(5) Atom $\% \mathrm{D}=\frac{\mathrm{R}}{\mathrm{R}+2.45} \times 100$.

Although this approximation is fairly good at low concentrations, it introduces an error of greater than 0.003 atom $\% \mathrm{D}$ at abundances greater than 0.500 atom \% D. In body water determinations with an injected dose of $100 \mathrm{gm}$. of $\mathrm{D}_{2} \mathrm{O}$, the concentrations found in the body fluids are considerably less than this a few minutes after the injection.

\section{c) Calculation of total body water volume}

In order to calculate total body water volume, the concentrations of $\mathrm{D}_{2} \mathrm{O}$ must be expressed as volume $\% \mathrm{D}_{2} \mathrm{O}$ which is calculated from the atom $\% \mathrm{D}$ as follows :

(6) Volume of $D_{2} O$ per mole water $=\frac{A \times M_{D}}{d_{D}}$, where: $\mathrm{A}=$ fraction of water present as $\mathrm{D}_{2} \mathrm{O}$, i.e., (atom $\% \mathrm{D}$ in excess of normal)/100.

$M_{D}=$ molecular weight of $\mathrm{D}_{2} \mathrm{O}$.

$\mathrm{dD}_{\mathrm{D}}=$ density of $\mathrm{D}_{2} \mathrm{O}$ at body temperature. 
(7) Volume of $\mathrm{H}_{2} \mathrm{O}$ per mole water $=\frac{(1-A)\left(M_{B}\right)}{d_{B}}$,

where: $\mathrm{M}_{\mathrm{B}}=$ molecular weight of $\mathrm{H}_{2} \mathrm{O}$.

$d_{\mathrm{H}}=$ density of $\mathrm{H}_{2} \mathrm{O}$ at body temperature.

(8) Volume $\% \mathrm{D}_{2} \mathrm{O}=\frac{\text { Volume of } \mathrm{D}_{2} \mathrm{O} \times 100}{\text { Volume of } \mathrm{D}_{2} \mathrm{O}+\text { Volume of } \mathrm{H}_{2} \mathrm{O}}$. Simplifying and substituting the constants:

(9) Volume $\% \mathrm{D}_{2} \mathrm{O}=\frac{100}{0.004+\frac{0.996}{\mathrm{~A}}}$.

Since only the deuterium concentration greater than normal abundance represents dilution by the body water, the excess of atom \% D enters into the equation." Our value for normal abundance is 0.0150 atom \% D.

(10) $A=\frac{\text { Atom \% D of the unknown }-0.0150}{100}$.

\section{CALIBRATIONS}

In final calculations for atom $\% \mathrm{D}$, it is necessary to take account of all the known sources of appreciable error, including particularly the nonuniformity of the resistor as a function of voltage already described, which can lead to an error proportional to concentration. Therefore, we have used the results of a series of calibration runs at concentrations up to 0.799 atom $\% \mathrm{D}$ to provide an empirical graphical relation between the measured $3 / 2$ ratio and atom $\% D$.

For the calibration, the operating conditions of the spectrometer were kept constant: an emission current of 12 microamperes, an accelerating voltage of $1750 \mathrm{~V}$, and the magnet settings necessary to obtain the maximum mass 3 and mass 2 peaks.

A series of five standards of known concentration were prepared gravimetrically from $99.87 \%$ $\mathrm{D}_{2} \mathrm{O}$. In order to compute the atom $\%$ concentration of the standards prepared, it is necessary to know the normal abundance of $\mathrm{D}_{2} \mathrm{O}$ in the distilled water used as determined by our instrument under the fixed conditions imposed. The average of 21 distilled water runs was 0.0150 atom \% D as shown in Table III. For comparison purposes, this average value can be expressed as one part $D$ in 6670. This is in excellent agreement with a

4 Below an atom \% D excess of 0.100 the volume \% $\mathrm{D}_{2} \mathrm{O}$ can be taken to be identical with the atom \% $\mathrm{D}$ excess. For concentrations between 0.100 and 0.300 atom $\% \mathrm{D}$ excess, the volume $\% \mathrm{D}_{2} \mathrm{O}$ is equal to the atom \% $\mathrm{D}$ excess plus 0.001 . For concentrations between 0.300 and 1.00 atom $\% \mathrm{D}$ excess, the volume $\% \mathrm{D}_{2} \mathrm{O}$ is larger by from 0.001 to 0.004 . ratio of one part in $6700 \pm 50$ determined by Voskuyl (31) and Greene and Voskuyl (32) in careful density measurements.

The normal abundance can be expressed in terms of weight $\% \mathrm{D}_{2} \mathrm{O}$ by the following equations :

(11) Weight $\mathrm{D}_{2} \mathrm{O}$ per mole water $=\frac{\text { Atom } \% \mathrm{D} \times \mathrm{M}_{\mathrm{D}}}{100}$.

(12) Weight $\mathrm{H}_{2} \mathrm{O}$ per mole water

$$
=\left(1-\frac{\text { Atom } \% \mathrm{D}}{100}\right) \times \mathrm{M}_{\mathrm{H}} \text {. }
$$

(13) Weight $\% \mathrm{D}_{2} \mathrm{O}=\frac{\text { Weight } \mathrm{D}_{2} \mathrm{O} \times 100}{\text { Weight } \mathrm{H}_{2} \mathrm{O}+\text { Weight } \mathrm{D}_{2} \mathrm{O}}$

We calculated the normal abundance for the distilled water used to be 0.0167 weight $\% \mathrm{D}_{2} \mathrm{O}$. The concentration of the $\mathrm{D}_{2} \mathrm{O}$ used in preparing the samples was checked from the weight of the volume delivered by a $25-\mathrm{ml}$. Bureau of Standards calibrated pipette and the density figures for $\mathrm{D}_{2} \mathrm{O}$ reported by Tronstad and Brun (33). From the known weights, concentrations and molecular weights of the $\mathrm{D}_{2} \mathrm{O}$ and water used in preparing the standards, the atom \% D of each standard was calculated by applying the following formula:

(14) Atom $\% D=\frac{100}{\frac{M_{D}}{M_{B}}\left(\frac{W_{1}+W_{2}}{W_{1} \cdot F_{D}+W_{2} f_{D}}\right)-\frac{M_{D}}{M_{B}}+1}$.

Where:
$\mathrm{W}_{1}=$ Weight of $\mathrm{D}_{2} \mathrm{O}$ in standard,
$\mathrm{W}_{2}=$ Weight of distilled water in standard,
$F_{D}=$ Weight fraction of $\mathrm{D}_{2} \mathrm{O}$ in the $\mathrm{D}_{2} \mathrm{O}$,
$f_{D}=$ Weight fraction of $\mathrm{D}_{2} \mathrm{O}$ in distilled water.

Since $F_{D}, f_{D}, M_{D}$, and $M_{H}$ are constants for the material and instruments used, the expression can be reduced to:

(15) Atom \% D

$$
=\frac{100}{(1.1117)\left(\frac{W_{1}+W_{2}}{0.9987 \times W_{1}+0.000167 \times W_{2}}\right)}-0.1117 .
$$

Table IV shows that the atom $\% \mathrm{D}$, after all corrections have been made, deviates significantly and progressively from the "true" value above a concentration of 0.100 atom \% D. Consequently,

TABLE III

Normal abundance of deuterium in hydrogen*

\begin{tabular}{c|c|c}
\hline \hline Date & No. runs averaged & Atom \% D \\
\hline $2 / 49$ & 6 & 0.0145 \\
$3 / 49$ & 5 & 0.0140 \\
$4 / 49$ & 4 & 0.0153 \\
$7 / 49$ & 3 & 0.0165 \\
$11 / 49$ & 3 & 0.0147 \\
\hline
\end{tabular}

Mean $=0.0150$

Standard deviation of the means $=\mathbf{0 . 0 0 0 8}$

Probable error $=0.0005$

* As measured under our conditions. 
TABLE IV

Calculated and "true" values of atom \% $D$

\begin{tabular}{l|c|c|c|c|c}
\hline \hline Date & $\begin{array}{c}\text { Stand- } \\
\text { ard }\end{array}$ & $R\left(\frac{\text { Mass 3 }}{\text { Mass 2 }}\right.$ 10-2 $^{-2}$ & $\begin{array}{c}\text { Measured } \\
\text { atom \% } \\
D^{*}\end{array}$ & $\begin{array}{c}\text { “True" } \\
\text { atom \% } \\
\text { D }\end{array}$ & $\Delta$ \\
\hline $4 / 5 / 49$ & No. 6 & 0.61 & 0.025 & 0.0248 & 0.000 \\
$4 / 4 / 49$ & No. 5 & 1.05 & 0.044 & 0.0452 & 0.001 \\
$4 / 9 / 49$ & No. 4 & 2.61 & 0.107 & 0.111 & 0.004 \\
$4 / 8 / 49$ & No. 3 & 8.78 & 0.350 & 0.401 & 0.051 \\
$4 / 10 / 49$ & No. 2 & 17.53 & 0.695 & 0.799 & 0.104 \\
\hline
\end{tabular}

* Calculated from Equation 4.

the calibration curve has been used as the basis of all our determinations. In Figure 3, the mass $3 /$ mass 2 ratios of the standards, plotted against the "true" atom $\% \mathrm{D}$, are seen to fall on a straight line. Table $\mathrm{V}$ shows that all of the standards were determined with a probable error of less than 0.004 atom \% D.

\section{ACCURACY OF THE METHOD}

The handling of body fluids is based on suggestions made by Rittenberg. The $0.03 \mathrm{ml}$. sample (urine or plasma) is pipetted into a platinum boat and placed in the inlet tube. The oxidizing furnace is kept off and no external heat applied in order to avoid combustion of organic volatile materials. The water of the sample is evaporated by and carried over in an oxygen stream and then

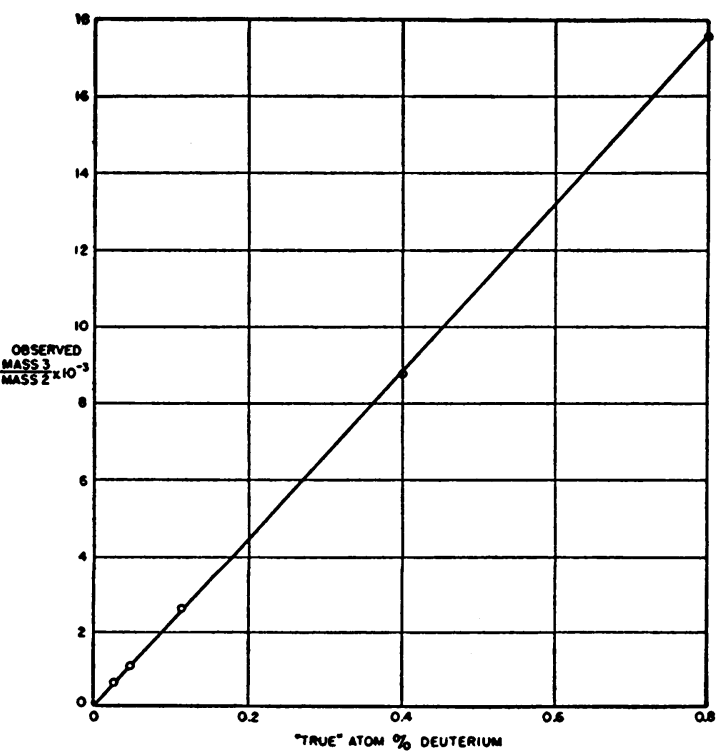

Fig. 3. Calibration Graph Showing Relation Between Mass 3/Mass 2 Ratio to "True" Atom \% D as Determined by Weighed Standards collected in a dry-ice trap, for a routine reduction. With this method no preliminary purification of the sample is necessary. In order to determine the completeness of recovery by this method, $99.87 \% \mathrm{D}_{2} \mathrm{O}$ was added in vitro to weighed amounts of serum and urine. In each case, an aliquot of $\mathrm{D}_{2} \mathrm{O}$ was diluted with triply distilled $\mathrm{H}_{2} \mathrm{O}$ as control. The $\mathrm{D}_{2} \mathrm{O}$ concentrations in the four specimens were then measured; the results

TABLE $V$

Reproducibility of atom \% $D^{*}$ in standards

\begin{tabular}{|c|c|c|c|c|c|c|}
\hline Date & $\begin{array}{c}\text { Stand- } \\
\text { ard }\end{array} \mid$ & $\begin{array}{c}\text { of } \\
\text { sam- } \\
\text { ples }\end{array}$ & Range & Mean & 。 & P.E. \\
\hline $\begin{array}{l}4 / 5 / 49 \\
4 / 4 / 49 \\
4 / 9 / 49 \\
4 / 8 / 49 \\
4 / 10 / 49\end{array}$ & $\begin{array}{l}\text { No. } 6 \\
\text { No. } 5 \\
\text { No. } 4 \\
\text { No. } 3 \\
\text { No. } 2\end{array}$ & $\begin{array}{l}5 \\
4 \\
4 \\
8 \\
8\end{array}$ & $\begin{array}{l}0.0220-0.0269 \\
0.0408-0.0445 \\
0.105-0.111 \\
0.350-0.367 \\
0.706-0.725\end{array}$ & $\begin{array}{l}0.0248 \\
0.0428 \\
0.107 \\
0.361 \\
0.716\end{array}$ & $\mid \begin{array}{l}0.00192 \\
0.00175 \\
0.0020 \\
0.0053 \\
0.0057\end{array}$ & $\begin{array}{l}0.00129 \\
0.00118 \\
0.0013 \\
0.0036 \\
0.0038\end{array}$ \\
\hline
\end{tabular}

* Calculated by Equation 5.

are listed in Table VI. These results indicate recovery of very close to $100 \%$ since the maximum difference between calculated and determined values is $2.0 \%$. Since an error of 0.004 atom $\%$ $\mathrm{D}$ would be equivalent to $2.0 \%$ at these concentrations, we can interpret these results either as

TABLE VI

Recovery of deuterium from plasma and urine

\begin{tabular}{c|c|c|c|c|c|c}
\hline \hline Date & Specimen & $\begin{array}{c}\text { No. } \\
\text { runs } \\
\text { aver- } \\
\text { aged }\end{array}$ & $\begin{array}{c}\text { Atom } \\
\% \text { D }\end{array}$ & $\begin{array}{c}\text { Deter- } \\
\text { mined } \\
\text { ratio }\end{array}$ & $\begin{array}{l}\text { Calcu- } \\
\text { lated } \\
\text { ratio }\end{array}$ & $\Delta \%$ \\
\hline $3 / 19 / 49$ & $\mathrm{H}_{2} \mathrm{O}$ Standard & 6 & 0.202 & & & \\
$3 / 23 / 49$ & Plasma & 4 & 0.192 & & & \\
\hline & & & & 0.954 & 0.947 & $0.8 \%$ \\
\hline $4 / 21 / 49$ & $\mathrm{H}_{2} \mathrm{O}$ Standard & 7 & 0.204 & & & \\
\hline & Urine & 7 & 0.198 & & & \\
\hline & & & & 1.03 & 1.01 & $2.0 \%$ \\
\hline
\end{tabular}

$100 \%$ recovery within 0.004 atom $\%$ error, or $98 \%$ recovery and no error in measurement.

The technique used to determine the reproducibility of our results is based on the use of calibration standards kept under anaerobic conditions. From Table VII, it can be seen that none of the determinations show a deviation from the mean greater than 0.003 atom $\% \mathrm{D}$. We have computed the standard error of the means and find 
TABLE VII

Reproducibility of standards

\begin{tabular}{c|c|c|c|c|c|c}
\hline \hline $\begin{array}{c}\text { Stand- } \\
\text { ard } \\
\text { number }\end{array}$ & Date & $\begin{array}{c}\text { No. } \\
\text { samples }\end{array}$ & $\begin{array}{c}\text { Mean } \\
\text { atom } \\
\% \text { D }\end{array}$ & Mean & $\begin{array}{c}\text { Differ- } \\
\text { ence from } \\
\text { the mean } \\
\text { No. 5 }\end{array}$ & $\begin{array}{c}\text { Standard } \\
\text { deviation } \\
\text { of the mean }\end{array}$ \\
\hline & $4 / 2 / 49$ & 4 & 0.045 & 0.044 & .001 & \\
& $6 / 14 / 49$ & 1 & 0.044 & & .000 & \\
$6 / 20 / 49$ & 2 & 0.042 & & .002 & \\
& $8 / 25 / 49$ & 3 & 0.047 & & .003 & \\
& $10 / 22 / 49$ & 3 & 0.041 & & .003 & \\
& $11 / 3 / 49$ & 3 & 0.044 & & .000 & 0.0019 \\
No. 3 & $4 / 8 / 49$ & 8 & 0.399 & 0.396 & .003 & \\
& $6 / 23 / 49$ & 2 & 0.393 & & .003 & \\
& $10 / 27 / 49$ & 4 & 0.395 & & .001 & \\
& $11 / 5 / 49$ & 3 & 0.396 & & .000 & \multirow{10}{*}{0.0021} \\
& $11 / 17 / 49$ & 3 & 0.398 & & .002 & 0.0021 \\
& & & & & & \\
\hline
\end{tabular}

that $95.5 \%$ of the data would be within 0.004 atom $\% \mathrm{D}$ of the mean. The distilled water samples as shown in Table III can also be considered as standards and it can be seen that more than $99 \%$ of the data would deviate less than 0.004 atom $\% \mathrm{D}$ from the mean.

These values of standard deviation show that determinations of $\mathrm{D}_{2} \mathrm{O}$ concentrations in body fluids are accurate to 0.004 atom $\% \mathrm{D}$. Therefore, for equilibrium concentrations of approximately 0.200 atom $\% \mathrm{D}$, the total body water values are accurate to within approximately 800 ml. To maintain a check on this accuracy, it is essential that periodic determinations of the calibration standards be carried out.

Successive measurements of the same sample will lead, of course, to a smaller value of standard deviation. Five successive runs on a sample of 0.3682 atom $\% \mathrm{D}$ gave a standard deviation of 0.0005 atom $\% \mathrm{D}$. In terms of the mass $3 /$ mass 2 ratio for this sample, which is 0.00810 , the standard deviation is 0.000001 .

\section{ACKNOWLEDGMENTS}

The authors wish to express their thanks to Dr. A. O. C. Nier, Dr. K. T. Bainbridge, and Dr. D. Rittenberg for their most helpful advice, to Mr. Frank J. Rennie for his major contributions to the completion of the spectrometer, and to Mrs. Donald Schoen, Miss Mary Powell Smythe, and Mr. David Caton for their constant hard work and willing assistance, both during the construction of the spectrometer and afterwards.

\section{BIBLIOGRAPHY}

1. Moore, F. D., The use of isotopes in surgical research. Surg., Gynec. \& Obstet., 1948, 86, 129.
2. Hevesy, G., and Hofer, E., Elimination of water from human body. Nature, 1934, 134, 879.

3. Hevesy, G., and Jacobsen, C. F., Rate of passage of water through capillary and cell walls. Acta physiol. Scandinav., 1940, 1, 11.

4. McDougall, E. J., Verzar, F., Erlenmeyer, H., and Gaertner, H., Heavy water in animal body. Nature, 1934, 134, 1006.

5. Moore, F. D., Determinations of total body water and solids with isotopes. Science, 1946, 104, 157.

6. Mitchell, H. H., Hamilton, T. S., Steggerda, F. R., and Bean, H. W., Chemical composition of adult human body and its bearing on the biochemistry of growth. J. Biol. Chem., 1945, 158, 625.

7. Pace, N., and Rathbun, E. W., Studies on body composition. III. The body water and chemically combined nitrogen content in relation to fat content. J. Biol. Chem., 1945, 158, 685.

8. Soberman, R. J., A comparison of total body water as determined by antipyrine and desiccation in rabbits. Proc. Soc. Exper. Biol. \& Med., 1949, 71, 172.

9. Soberman, R., Brodie, B. B., Levy, B. B., Axelrod, J., Hollander, V., and Steele, J. M., The use of antipyrine in the measurement of total body water in man. J. Biol. Chem., 1949, 179, 31.

10. Pace, N., Kline, L., Schachman, H. K., and Harfenist, M., Studies on body composition. IV. Use of radioactive hydrogen for measurement in vivo of total body water. J. Biol. Chem., 1947, 168, 459.

11. Flexner, L. B., Gellhorn, A., and Merrell, M., Studies on rates of exchange of substances between the blood and extravascular fluid. J. Biol. Chem., 1942, 144, 35.

12. Schoenheimer, R., and Rittenberg, D., Deuterium as an indicator in the study of intermediary metabolism. J. Biol. Chem., 1935, 111, 163.

13. Ussing, $H$. H., Exchange of $H$ and $D$ atoms between water and protein in vivo and in vitro. Skandinav. Arch. f. Physiol., 1938, 78, 225.

14. Smith, P. K., Trace, J., and Barbour, H. G., The fate of deuterium in the mammalian body. J. Biol. Chem., 1936, 116, 371.

15. Schloerb, P. R., Friis-Hansen, B. J., Edelman, I. S., Solomon, A. K., and Moore, F. D., The measurement of total body water in the human subject by deuterium oxide dilution. J. Clin. Invest., 1950, 29, 1296.

15a. Rittenberg, D., and Graff, S., In preparation.

16. Nier, A. O. C., A mass spectrometer for isotope and gas analysis. Rev. Scient. Instruments, 1947, 18, 398.

17. Gibson, R. J., Jr., The pumping speed of an oil-diffusion pump for hydrogen. Rev. Scient. Instruments, 1948, 19, 276.

18. Setlow, R. B., Pumping speed of an oil diffusion pump for hydrogen. Rev. Scient. Instruments, 1948, 19, 533.

19. Fluke, D., A comparison of mercury diffusion pump- 
ing speed for five gases. Rev. Scient. Instruments, 1948, 19, 665.

20. Dayton, B .B., The speed of oil and mercury diffusion pumps for hydrogen, helium and deuterium. Rev. Scient. Instruments, 1948, 19, 793.

21. Jordan, E. B., and Coggeshall, N. D., Measurement of relative abundance with the mass spectrometer. J. Applied Physics, 1942, 13, 539.

22. Urey, H. C., Isotopic exchange reactions. Record of Chemical Progress, 1948, Summer Issue, p. 69.

23. Honig, R. E., A comparison of ionization cross sections of $\mathrm{H}_{2}$ and $\mathrm{D}_{2}$. J. Chem. Physics, 1948, 16, 837.

24. Bauer, N., and Beach, J. Y., Differences in mass spectra of $\mathrm{H}_{2}$ and $\mathrm{D}_{2}$. J. Chem. Physics, 1947, 15, 150.

25. Friedel, R. A., and Sharkey, A. G., Jr., Mass spectrum of hydrogen deuteride (HD). J. Chem. Physics, 1949, 17, 584.

26. Inghram, M. G., The isotopic constitutions of tungsten, silicon and boron. Physical Rev., 1946, 70, 653.
27. Honig, R. E., Gas flow in the mass spectrometer. J. Applied Physics, 1945, 16, 646.

28. Bleakney, W., A search for isotopes of hydrogen and helium. Physical Rev., 1932, 41, 32.

29. Rittenberg, D., The preparation of gas samples for mass spectrographic isotope analysis, in: Preparation and Measurement of Isotopic Tracers. J. W. Edwards, Ann Arbor, Mich., 1946, p. 31.

30. Rittenberg, D., Bleakney, W., and Urey, H. C., The equilibrium among three hydrogens. J. Chem. Physics, 1934, 2, 48.

31. Voskuyl, R. J., The deuterium-protium ratio in natural waters. Thesis, Harvard University, 1938.

32. Greene, C. H., and Voskuyl, R. J., The deuteriumprotium ratio. I. The densities of natural waters from various sources. J. Am. Chem. Soc., 1939, 61, 1342.

33. Tronstad, L. T., and Brun, J., Precision determinations of the densities of $\mathrm{D}_{2} \mathrm{O}$ and $\mathrm{H}_{2} \mathrm{O}$. Electrolytic separation of oxygen isotopes. Trans. Faraday Soc., 1938, 766, 34.

\section{SPECIAL NOTICE TO SUBSCRIBERS}

Post Offices will no longer forward the Journal when you move.

Please notify Journal of Clinical Investigation, Business Office, c/o Cincinnati General Hospital, Cincinnati 29, Ohio, at once when you have a change of address and do not omit the zone number if there is one. 